\title{
Beliefs and Traditions Related to a Child's First Year of Life: A Study of the North-west of Portugal
}

\author{
Paula Cristina Almeida Remoaldo and \\ Elódia Eulália Lopes Canteiro
}

In this paper we propose an approach to investigate, in the North-west of Portugal, the parents' behaviour at birth and during the first year of life of their children. We compare the heritage, specifically the beliefs and traditions, with the changes that resulted from the recent and deep cultural transformations that have taken place in Portugal in the last few decades. In parallel, we tried to determine if the parents' behaviours, based on beliefs and traditions, can affect the children's health. We based our investigation on standardized interviews with 76 mothers of one-year-old children (born between January and December 2001) who lived in two parishes of Vizela city. This is a territory where a more traditional way of life prevails than in other territories of the centre and south of the country, where there is a strong attachment for religious and social values and where the influence of the ancestral traditions is still alive. The paper concludes that cultural heritage can have important impact on individual health. Health professionals, who work in primary care and in hospitals, must be aware of the responsibility they have to change this scenario.

The revolution of April 1974 led to two decades of deep social and cultural changes in Portuguese society, which are expressed, among other ways, in the spectacular decrease of the Infant Death Rate to similar values of those of the more developed countries.

Until the 1980s, Portugal had very high values compared to the European Union average. In 1960, about 78 children died before one year of age for each 1000 born

Correspondence to: Paula Cristina Almeida Remoaldo, Departamento de Geografia, Universidade do Minho, Campus de Azurém, 4810 Guimarães, Portugal. Tel.: +351-253-510563/560; Fax: +351-253-510 569; Email: premoaldo@geografia.uminho.pt 
alive, while in the European Union the average was 34.5\% (EUROSTAT 2000). By 1992, Portugal managed to fall below the barrier of $10 \%$, which meant that the country was finally a developed one. The more determinant factors for this decline were the increase of the level of education and the improvement of quality of life and of the Portuguese health system, owed to Primary Healthcare, especially from the beginning of the 1970s. It is important to point out that since 1998 Portugal has left the last place in the group of the 15 countries of the European Union, overtaking Ireland, Greece and the United Kingdom.

In spite of the tendency towards the homogeneity of values, the regional specificities continue to be significant, with the evidence of a dichotomy between the North and the South of continental Portugal.

This assumed cleavage between North and South reveals multiple factors that interacted along an extended period of time. In the North, the influence of a more traditional way of life, characterized by a strong attachment to religious and social values, which might had a negative impact in the individual and volunteer use of the public health services, stands out. By itself, the influence of this factor was more outstanding than the parents' poverty or education level. So, the higher socioeconomical level of the North did not overcome the strong influence of the religious and social values, while in the South the minor importance of these values counterbalanced their greater economic debility.

In spite of the health system's evolution, and of the great quantity of information provided by different sources, we are frequently faced, in the studied territory, with maternal behaviours full of symbolism that can only be explained by tradition and cultural heritage (Le Breton 1988; Gouzilh 1994). The lack of empirical studies on this matter, namely the more recent works of compilations of beliefs, of themselves based on reference works (Braga 1924; Joaquim 1983; Vasconcelos 1982-1986, 1988; Brito 1986; Barbaut 1990; Neves 1994; Canavarro 2001; Remoaldo 2002), has encouraged us to proceed with this effort to confront the cultural inheritance of the cultural changes that have characterized the Portuguese society.

\section{Methodology}

To check the persistence of myths, beliefs and traditions regarding the period from birth until the first birthday of a child, we chose to study mothers of one-year-old children who live in the parishes of S. Miguel and S. João in the city of Vizela (Northwest of Portugal). We used directive or standardized domiciliary interviews (Ghiglione \& Matalon 1992). There are several disadvantages that can be pointed out about this technique, but because we are dealing with a quantitative study, we chose it because it is similar to an inquiry by questionnaire. While the inquiry by directive or standardized interview assume a face-to-face conversation that can assure that it was really the mother who answered the inquiry, the inquiry by questionnaire does not imply the presence of the inquirer. On the other hand, knowing the characteristics of the Portuguese population, the number of skewed results obtained would be probably higher, for example, because mothers could ask 
relatives for help to fill the questionnaire. At least the interview option allowed us to retain some narratives that would not have been revealed if we had chosen another technique.

During 2001, in the municipality of Vizela, 255 infants were born alive, of which 110 were born in the two studied parishes. This value represents $43 \%$ of the bornalive infants in this municipality. We chose to interview mothers of all the children that were one year old up until 31 July 2002. We did 76 interviews, representing 69\% of the born-alive infants of the two parishes ( 26 from the parish of S. João and 50 from the parish of S. Miguel). The sources used were the registers available at the Civil Registry Offices of Vizela and Guimarães and the data published in the Demographic Statistics of the National Institute of Statistics (Instituto Nacional de Estatística 2002). We consider the selected sample representative, in terms of volume and in what it concerns the socio-economical characteristics of the universe, as we could confirm by the results of the last General Census of the Population-Census 2001. In terms of volume, it is essential to accomplish the criteria of the representativeness of 0.95 (Ghiglione \& Matalon 1992), pre-supposing a type error of $5 \%$. So, regarding a confidence interval of $95 \%$, in a sample of 76 born-alive and having as reference a universe of 110 born-alive, the type error is approximately 0.056, which is a limited error in statistical terms.

Contrary to what happens in other countries, the Portuguese population, and more specifically the Portuguese north-west population, easily participates in interviews concerning infant health (Remoaldo 2002); this was corroborated by the insignificant number of refusals (only one mother refused to participate). The approach and the interaction done by one of the members of the research team were facilitated by the openness to this kind of study and by the ease of communication, typical of the Portuguese north-west population.

Since we are dealing with a conservative population, when compared to the population of other European countries, we chose to interview the mothers because they follow, in a more active way, the growth and the development of the child. The law regarding maternity leave changed in Portugal in the final years of the twentieth century, allowing a higher involvement of the father in the first four months of life of the child and including the possibility of replacing the mother on maternity leave. But the fact is the mother still continues to be the one to stay at home, following closely the growth and development of the child, during the 120 days granted to this effect.

The main variables we took into account in the investigation were the age, the level of instruction and the mothers' profession. In our opinion the age can be relevant, because older mothers tend to be more conservative and tend to reproduce traditional behaviours (Remoaldo 2002). In the sample the women were mainly between 21 and 30 years of age (66.6\%). About 93.3\% were between 21 and 35 years of age, and the oldest woman was 41 years old.

These results reveal a higher concentration in younger ages than in the other countries of the European Union. 


\section{Results}

All the levels of instruction were representative in the sample with special attention to the low ones (Table 1 ). We had $56 \%$ of the mothers $(n=42)$ with up to six years of instruction. Nevertheless, $9.3 \%(n=7)$ of the mothers had a university degree. Also, $90.7 \%$ of the mothers had an occupation; the majority of the fathers had an occupation $(96.0 \%)$ and only $2.7 \%$ were unemployed (Table 2 ).

Most of the parents, either the mother $(53.4 \%, n=40)$ or the father $(46.6 \%$, $n=35$ ), worked in industry (factories or handicraft). Some of these were not qualified workers (eight mothers and four fathers). In second place we had mothers with administrative functions $(13.3 \%, n=10)$ and in third place intellectual and scientific activities $(10.7 \%, n=8)$. Some investigators (e.g., Masuy-Stroobant 1988) have been alerted to the fact that factory workers are a risk group for infant morbidity and infant mortality. The explanation of this is centred on the bad work conditions, with special attention to the long and continuous hours of work.

Nevertheless, in our opinion, the unemployed mothers or the domestic ones can be considered a more problematic group, because they don't have any legal support concerning either pregnancy or maternity. They have fewer opportunities to talk and exchange information about maternity questions with other women. When we are considering the behaviours associated with beliefs and traditions, the isolation, the lack of dialogue and the lack of sharing of experience can contribute to their persistence.

Table 1 Mother's and Father's Education Levels

\begin{tabular}{|c|c|c|c|c|}
\hline \multirow[b]{2}{*}{ Education level } & \multicolumn{2}{|c|}{ Mother } & \multicolumn{2}{|c|}{ Father } \\
\hline & $n$ & $\%$ & $n$ & $\%$ \\
\hline $\begin{array}{l}\text { Knows how to read and write without } \\
\text { frequent attendance at any education system }\end{array}$ & 0 & 0.0 & 1 & 1.3 \\
\hline Four years & 19 & 25.3 & 17 & 22.7 \\
\hline Six years & 23 & 30.7 & 28 & 37.3 \\
\hline Nine years & 7 & 9.3 & 8 & 10.7 \\
\hline Twelve years & 18 & 24.0 & 14 & 18.7 \\
\hline Polytechnic & 1 & 1.3 & 0 & 0.0 \\
\hline University level & 7 & 9.3 & 7 & 9.3 \\
\hline Total & 75 & 100.0 & 75 & 100.0 \\
\hline
\end{tabular}

Table 2 Mother's and Father's Occupation

\begin{tabular}{lcccr}
\hline & Mother & $\%$ & Father & $\%$ \\
\hline Employed & 68 & 90.7 & 72 & 96.0 \\
Unemployed & 7 & 9.3 & 2 & 2.7 \\
Without information & - & 100.0 & 75 & 1.3 \\
Total & 75 & & 100.0 \\
\hline
\end{tabular}


In the North-west of Portugal, the high involvement of women in the workplace is only possible because of the existing family strategies. The support of the grandmothers during the day must be emphasized, as we know that institutional support is inadequate. Another significant fact is that $20.0 \%$ of the families of our sample were living with in their parents (i.e., as a large family). The family influence seems to be very strong as the mothers told us frequently 'we do everything like the ancients did and we first speak with our mother before going to the doctor'. This narrative allows us to deduce that there is a direct relation between the transmission of traditional knowledge and the co-habitation regime, which the family links allow.

Among the rituals that appear to be more significant to understand a specific community, we include those associated, after the birth, to outstanding moments during the first year of life: the first bath at home (the very first bath is at the hospital), the baptism ceremony and the baby's first steps. The birth, although it continues implicitly to have the feeling of a unique moment, has been gradually losing its magic and mysticism, to become more and more technical-all the interviewed mothers had their children in hospitals $(93.3 \%$ in public hospitals and $6.7 \%$ in private hospitals and clinics).

Regarding the first bath at home, we encountered a considerable number of mothers $(25.0 \%, n=19)$ that used inherited procedures from mothers/mothers-inlaw that are still common today. One of these procedures is associated with the fear of water that the new-born can retain into adulthood, so mothers throw the water used on the bath to the street, in the brook or down the toilet, but always throwing it upwards so that the child will lose its fear. Another curious aspect, although less common, is associated with speech development. While the child is bathed, not only for the first bath, but until the child starts to speak, the mother or the grandmother, with the same water that washed the child, washes her mouth, saying 'water of washed ass, for you to soon speak and speak well' (Braga 1924, p. 50).

The idea that the new-born, before he or she is baptized, is exposed to evil powers (i.e., the body is open) is prevalent in the studied territory. With the baptism ritual, beyond the effective integration in society, namely in the religious community, there is also the feeling of liberation from original sin. It should be pointed out that $57.4 \%$ of baptism ceremonies took place in the first four months of life of the children and that the percentage of children not baptized was very low (about $4 \%$ ), which is in conformity with the fact that more than $90 \%$ of the population of this territory is Catholic. During the time between the birth and the baptism, 33 mothers (44\%, $n=75$ ) revealed that they took special precautions. Of these, the more significant have to do with the preservation of the child, keeping it away from external effects. That is the reason 33 mothers (44\%) declared they avoided going out with the child (26 of the mothers had less than seven years of schooling) and 25 mothers $(33.3 \%)$ did not take the child to the church, as can be seen in Figure 1.

The most common procedure against external threats, still a routine for 19 of the interviewed mothers $(25.3 \%)$, is the use of salt and a box of matches, both of which should always accompany the child when he or she goes out, particularly at night and while the child is unbaptized. There are also other precautions that are expressed in the concern of not placing the clothes of the new-born on balconies, or in the street, 


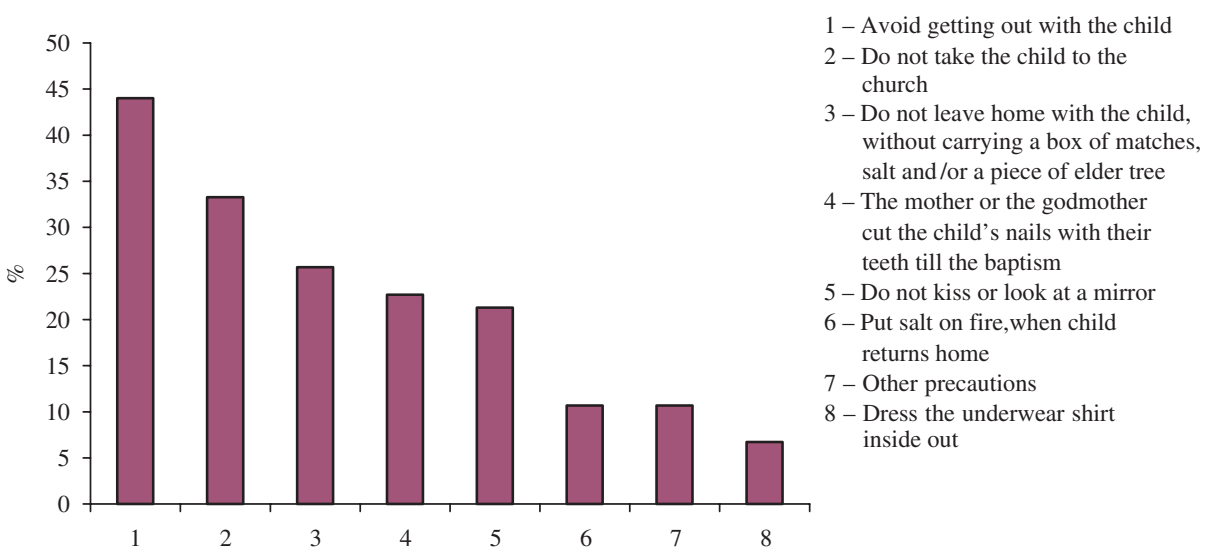

Figure 1 Special Precautions with the Child Until the Baptism Ceremony

between nightfall and dawn, which is related to the fear of the negative effects of the moon (i.e., it can lead to several diseases), or to the protection against evil eye and witchery, using special small medals, for example, the Agnus Dei, held by a safety-pin in the underwear of the baby, or the little bag, ${ }^{1}$ that the baby should always carry with him or her, until the baptism.

Our greater surprise was that 17 mothers $(22.7 \%)$ said that they or the godmothers cut the nails of the baby with their own teeth, until the baptism, so that the baby will not become a thief and will not take too long to start to speak. Although we knew of this procedure (Remoaldo 2002), we did not imagine that it still had so much importance in the studied territory. Although not much more significantly, the S. João parish shows a higher persistency of this procedure, with $26.9 \%$ versus $20.8 \%$ in S. Miguel.

The number of mothers who did not allow the child to kiss or look at a mirror $(21.3 \%, n=16)$ is also of significance; this behaviour was justified by the fear that the child would not speak when adult. Putting salt on the fire to protect against envy, when the child, after going out, comes back home, although less important, is still a procedure used in the studied area by $10.7 \%$ of the mothers $(n=8)$.

During the development of the questionnaire and based on readings, we supposed that, as baptism is a purification ritual that releases the new-born from impurity, it would be associated with a great level of mysticism. The implementation of the questionnaire revealed that it is no longer usual to follow rules like the mother cannot enter inside a church because of her state of impurity, which is only overcome 40 days after giving birth, or a child who is going to be baptized cannot enter inside the church by the side doors (Brito 1991). The questionnaire showed that the parents (instead of the godparents or the grandparents), are increasingly choosing the name they want for their children, the clothes they want them to wear, when they are going to be baptized and the date for the ceremony.

After baptism, there is a decrease in worries about external evil threats, but some rituals persist and are maintained until the child completes one year of age, as we can see in Figure 2. 


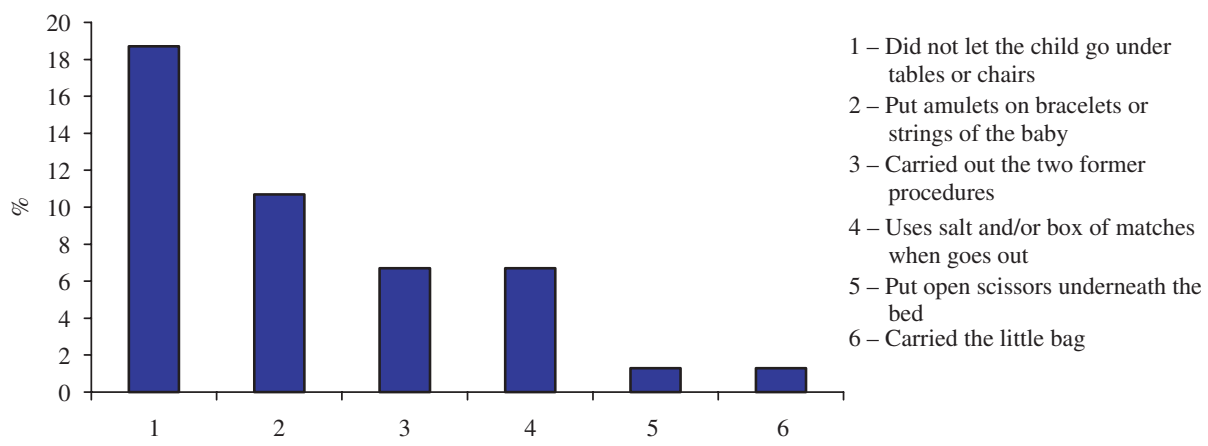

Figure 2 Special Precautions with the Child During the First Year of Life

Among these procedures we can see a special emphasis on not letting the child go under a table or chairs, since this action is associated with having walking problems in the future.

The beliefs related to the act of putting amulets on bracelets or strings of the baby, using salt and/or box of matches when he or she goes out (until the child completes one year of age), putting open scissors underneath the bed and the little bag, are associated with mysticism and with the supernatural, which is still well established in this territory as $14.3 \%$ of mothers studied at S. Miguel and $7.7 \%$ at S. João reproduced these kinds of behaviours. When we try to question and understand the causes of this kind of procedure, we obtained systematically as an answer 'the ancestors are the ones who knew, if they did it this way and nothing happened to them, we should do the same things'. We can infer that these procedures and beliefs, associated with the supernatural, are not explainable. They persist and reproduce themselves throughout generations, but they are not questionable by those who implement them. But we must take into account that these practices do not have a negative influence on the health of the child.

In what concerns the monitoring of the physical and psycho-motor development of the child, throughout his or her first year of life, we concluded that the majority of mothers $(58.7 \%, n=44)$, whether at the parish of S. João $(61.5 \%, n=16)$ or at S. Miguel $(57.1 \%, n=28)$, chose a private doctor/paediatrician (Table 3$)$.

About $20 \%$ of the mothers $(n=15)$ visited their family doctor (in a Public Health Centre), and a greater number of them had a low level of education (of the 15 mothers, 14 had six years of education, nine had only four years of education and just one had an university degree). We noticed that the families with unemployment problems, or with low income activities, such as factory workers, are the ones that use this kind of service. We cannot establish a strong connection between the sought services and the parents' working activity, perhaps because there is a general idea that if the child is followed by a medical specialist (private doctor) he or she will have better medical assistance. Based on such conviction, some families make an important monetary effort so they can provide what they think is better for the new-born. 
Table 3 Health Seeking

\begin{tabular}{|c|c|c|c|c|c|c|}
\hline Parish & Private doctor/paediatrician & $\%$ & Family doctor & $\%$ & Family doctor/hospital & $\%$ \\
\hline S. Miguel & 28 & 57.1 & 9 & 18.4 & 12 & 24.5 \\
\hline S. João & 16 & 61.5 & 6 & 23.1 & 4 & 15.4 \\
\hline Total & 44 & 58.7 & 15 & 20.0 & 16 & 21.3 \\
\hline
\end{tabular}

As Sudden Infant Death Syndrome is an important cause of infant death in developed countries and as the investigation done in the North-west of Portugal by Remoaldo showed that in the mid-1990s the information transmitted by health technicians was not followed by all parents, we asked some questions about this problem.

Sudden Infant Death Syndrome has been a subject of research during recent years (e.g., Guimarães \& Dehan 1994; Hunt 1995; Klonoff-Cohen \& Edelstein 1995; Meslé 1996; Dubru \& Ravet 1998) but the risk factors that are associated with it are not completely explained. However, there is a connection established between the sleep position of the child and a greater incidence of this syndrome, namely when the child sleeps in the ventral decubitus position. The Portuguese Department of Health, following the April of 1992 recommendation of the American Academy of Pediatrics, started to advise parents to lay down their children, preferably using the sideways or the dorsal decubitus positions. We can associate with this problem other behaviours that might have a considerable influence, such as the use of a pillow, smoking near the child and over-heating the child's room.

Regarding the child's sleeping position, the majority of mothers $(62.7 \%$ - see Table 4) follow the instructions given by the doctors and nurses at the hospital, although mothers with a higher level of education (university degree, $n=7$ ), are divided between the information given by the paediatrician (three mothers) and their own experience and/or consulted bibliography (four mothers). Just $2.7 \%$ of mothers continue to adopt a risky procedure, which, according to them, was advised by doctors or by nurses.

These results show that in recent years the information was transmitted and absorbed in an effective way, by health technicians and mothers, the opposite of what had been diagnosed by other investigations in the mid-1990s (Remoaldo 2002).

The use of a pillow while the child is sleeping is another of the risk factors commonly diagnosed. A significant number of mothers have adopted this risky behaviour, since $32.8 \%(n=22)$ used a pillow when the child slept. Such occurrence constitutes a motive of concern, although there is not a strong correlation between this practice and the ventral decubitus sleeping position, where the risk could be higher (Guimarães \& Dehan 1994; Willinger et al. 1994). When we established the correlation between the use of a sleeping pillow and the mother's level of education we concluded that it was mainly the mothers with a lower level of education $(24.9 \%$, $n=16$ ) who used this kind of procedure. 
Table 4 Position on which a Child Slept During the First Year of Life, According to the Person Who Advised the Mother, 2001

\begin{tabular}{|c|c|c|c|c|c|c|c|c|c|c|c|c|}
\hline \multirow{2}{*}{$\begin{array}{l}\text { Who advised } \\
\text { the position }\end{array}$} & \multicolumn{2}{|c|}{$\begin{array}{l}\text { On ventral } \\
\text { decubitus }\end{array}$} & \multicolumn{2}{|c|}{$\begin{array}{l}\text { On dorsal } \\
\text { decubitus }\end{array}$} & \multicolumn{2}{|c|}{ On side } & \multicolumn{2}{|c|}{$\begin{array}{l}\text { On ventral } \\
\text { decubitus and } \\
\text { sideways }\end{array}$} & \multicolumn{2}{|c|}{$\begin{array}{l}\text { Other } \\
\text { position }\end{array}$} & \multicolumn{2}{|c|}{ Total } \\
\hline & $N$ & $\%$ & $N$ & $\%$ & $N$ & $\%$ & $N$ & $\%$ & $N$ & $\%$ & $N$ & $\%$ \\
\hline The doctor or nurse & 2 & 2.7 & 2 & 2.7 & 42 & 56.0 & - & - & 1 & 1.3 & 47 & 62.7 \\
\hline $\begin{array}{l}\text { The mother of } \\
\text { the child }\end{array}$ & - & - & 1 & 1.3 & 13 & 17.3 & 3 & 4.0 & 3 & 4.0 & 20 & 26.6 \\
\hline $\begin{array}{l}\text { Position chosen } \\
\text { by the child }\end{array}$ & - & - & 2 & 2.7 & - & - & - & - & - & - & 2 & 2.7 \\
\hline Relatives & - & - & - & - & 4 & 5.3 & - & - & - & - & 4 & 5.3 \\
\hline $\begin{array}{l}\text { Consulted } \\
\text { bibliography }\end{array}$ & - & - & - & - & 2 & 2.7 & - & - & - & - & 2 & 2.1 \\
\hline Total & 2 & 2.7 & 5 & 6.7 & 61 & 81.3 & 3 & 4.0 & 4 & 5.3 & 75 & 100.0 \\
\hline
\end{tabular}

In what concerns the activity of smoking near the baby, we found just two cases in which mothers frequently smoke near the baby: a mother with four years of education and the father with six years of education; and a mother and a father both with university degrees. Regarding the mothers' age, one was 29 years old and the other was 34 years old. With this result we can conclude that, with some caution due to the low quantitative levels, there is no relationship between this procedure/ behaviour and the level of education or the age of mothers.

We did not find, in this sample, any reference to procedures related to the use of alcoholic drinks mixed with sugar or honey, where the dummy was moistened. We believe we are able to conclude that these procedures have been replaced by the general use of Dimeticone $(57.3 \%, n=43)$, acting as a tranquilizer and, according to mothers, prescribed by the doctor.

\section{Discussion}

When we crossed the different variables considered in the inquiry, which are related to the infant development and welfare, we did not find a strong correlation between the mothers' behaviours and the mothers' level of education and/or age. We also did not find any remarkable differences between the two parishes analysed. We are in the presence of aspects that traverse different ages, levels of education and socioprofessional occupations. We consider that, in this domain, there is a great concern to provide the best for the new-born children, which is associated with the children being followed by a doctor.

As to preventive behaviours related with the Sudden Infant Death Syndrome, we diagnosed a good knowledge and support from parents of the rules issued by the Department of Health, on the Bulletin of Infant and Juvenile Health, especially with regard to the sleeping position. We did not find similar knowledge and/or support 
for the procedures relating to the use of a sleeping pillow; as it is urgent to change this procedure, the information must reach the appropriate personnel. Regarding smoking near the child, we did not find evidence that this could cause an increase risk of the referred syndrome.

The same cannot be said when we analysed the variables related to beliefs and traditions. The main conclusion that we can draw from this study, relatively to associated behaviours due to strong cultural heritage, is that some myths, beliefs and traditions associated with birth and the first year of life are still much alive in this territory. We also confirmed a higher persistence of the quoted behaviours in mothers with no formal education. Strong familiar relationships and the fact that a significant number of families are very large seem to be the reason for these behaviours. The most common way of protection in this territory, especially until the baptism, is the box of matches that should always be with the child, whenever she abandons the safety of home. Finally, we can affirm that the persistence of traditions and beliefs in the city of Vizela continues to be relevant. In spite of their unscientific explanation, they have no negative effects on children's health. Nevertheless it is pertinent to alert the health professionals so that they can consider these cultural aspects in a perspective of health education, within the scope of the pre-natal and infant health consultations.

\section{Conclusions}

This empirical work was concerned with a geographic area of heavily industrialized traditional sectors that demand a lot of workers. The great majority of the population does not finish their studies, dropping out of school while they're still children, so that they can to go to work. This allows them to marry very young and to have their first child early in life. They are subjected to huge pressure from their family or from the Portuguese society in general to do so. As the salaries in industry are low in general, the women frequently work to supplement the low earnings of the family. These are some examples of the traditional culture of the North-west of Portugal. Other signs of this traditional culture include mainly Catholic weddings, a low rate of divorce and high religious devotion.

The main benefit to the women who work outside the home is the protection of the law and the access to a large quantity of information. The sources of information are multiple, with special emphasis on the contacts they maintain with other women and the sharing of maternal experience.

We tried to analyse the preventive behaviours of the child's parents during the first year of life and the type of influence the myths, beliefs and traditions have in the parents' procedures. Concerning the preventive behaviours related to Sudden Infant Death Syndrome, we observed a good knowledge and practice of the parents following the rules issued by the Department of Health, on the Bulletin of Infant and Juvenile Health, especially concerning the sleeping position. We cannot say the same about the use of a sleeping pillow. Our main finality is to alert the Health Ministry 
and the Braga Health Sub-Region of this irregularity. We also need to alert them of the need for a more emphatic relationship to be established between health professionals and patients, especially those who have lower levels of education. In Portugal it was recently proved that health professionals tend to establish a hierarchic relationship with the patient, especially with those with low levels of education (Remoaldo \& Costa 2002). This makes it more difficult for the patients to transmit their fears. There is also a need for the scientific explanation of the myths transmitted mainly by their mothers or mothers-in-law. In addition, the university curricula of the Medicine degree must be changed to become more focused on the teaching of the ability to interact with patients.

As we said before, we confirmed a higher persistence of myths and traditions in the behaviours of parents with a low level of education. The strong family relationship and the existence of a great number of large families are strong reasons for the replication of these behaviours.

In the age of globalization, the cultural differences assume a particular importance in the explication of phenomena apparently homogeneous. When the social and scientific mechanisms cannot give an answer to such fundamental questions as the preservation of life, the human being embraces the supernatural, the religious, the mythic, searching solutions to his or her limitations...

\section{Acknowledgements}

This study was backed by the Historical and Social Sciences Investigation Centre of the University of Minho. The authors wish to express their gratitude to this Investigation Centre and to the 75 mothers who participated on the study and shared with us the wonderful experience of motherhood. They also want to thank Elsa Lechner for her help on earlier versions of the manuscript.

\section{Note}

[1] Small bag that is held on the underwear, in the baby carriage or in the basket of the child and which is woven by a woman who is an 'expert in the matter', who prays and puts ashes, some herbs and salt inside, and that should be carried by the baby until baptism, without getting wet.

\section{References}

Braga, A. V. de (1924) De Guimarães: Tradições e usanças Populares (da terra, do trabalho, da mulher, do amor, do casamento, da morte, do céu-vária), vol. 1, Livraria Espozendense, Esposende.

Brito, J. (ed) (1991) Portugal Moderno: Tradições. Enciclopédia Temática, Pomo. Edições Portugal Moderno, Lisboa, pp. 11-18.

Canteiro, E. E. (2003) Evolução da Mortalidade Infantil e Práticas Associadas ao Primeiro ano de vida - um Estudo no Território de Vizela, Mestrado em História das Populações, Universidade do Minho, Guimarães.

Dubru, J. M. \& Ravet, F. (1998) 'Comportements parentaux et sommeil du nourrisson', Génération ONE - Le Journal Des Professionnels de la Petite Enfance, vol. 1, pp. 15-20. 
Eurostat (2000) Eurostat Annuaire-vue Statistique Sur l'Europe, Luxembourg.

Ghiglione, R. \& Matalon, B. (1992) O Inquérito: Teoria e Prática, 3rd ed., Celta Editora, Oeiras.

Gouzilh, N. (1994) 'Rites et représentations autour des douleurs de l' accouchement: le mal joli', Revue Soins Gynécologie, Obstétrique, Puériculture, Pediatrie, no. 151/152, pp. 39-48.

Guimarães, H. \& Dehan, M. (1994) 'Sleep positions and risks of sudden deaths in infants', Arquivos de Medicina, Porto, vol. 8, no. 5, pp. 309-310.

Hunt, C. E. (1995) 'Sudden infant death syndrome and subsequent sibilings', Pediatrics, vol. 95, no. 1, pp. 430-432.

Instituto Nacional de Estatística (2002) Estatísticas Demográficas, Lisboa.

Joaquim, T. (1983) Dar à luz, Ensaio Sobre as Práticas e Crenças da Gravidez, Parto e Pós-parto em Portugal, Publicações Dom Quixote, Lisboa.

Klonoff-Cohen, H. \& Edelstein, S. L. (1995) 'Bed sharing and the sudden infant death syndrome', British Medical Journal, vol. 311, November, pp. 1269-1272.

Le Breton, D. (1988) Corps et Sociétés: Essai de Sociologie et D'anthropologie du Corps, Méridiens-Klincksieck, Paris.

Masuy-Stroobant, G. (1988) 'Santé de l'enfant et inégalités sociales', in Une Enquête Dans le Hainaut sur le Comportement Préventif Des Mères, Rapport POLIWA 3, CIACO Éditeur, Louvain-la-Neuve.

Meslé, F. (1996) 'Mortalité infantile: Une chute spectaculaire', in Population. L'état des connaissances: la France, l'Europe, le monde, ed Institut National d'Etudes Démographiques, Édtions La Découverte, Paris.

Remoaldo, P. C. (2002) Desigualdades Territoriais e Sociais Subjacentes à Mortalidade Infantil em Portugal, Série Textos Universitários de Ciências Sociais e Humanas, Fundação Calouste Gulbenkian, Ministério da Ciência e da Tecnologia (Fundação para a Ciência e a Tecnologia), Lisboa.

Remoaldo, P. C. \& Costa, M. E. (2002) 'Equidade no acesso aos cuidados de saúde-resultados de dois inquéritos realizados à população' in Actas do Colóquio Internacional de Saúde e Discriminação Social, eds Maria Engrácia Leandro, et al., Braga, Instituto de Ciências Sociais, Universidade do Minho, pp. 71-90.

Vasconcelos, J. L. de (1986) Tradiçôes Populares de Portugal, Org. Guerreiro, M. Viegas, 2nd edn, Imprensa Nacional—Casa da Moeda, Lisboa. 